$6 \mid 2010$

Varia

\title{
La Lumière Complexe
}

\section{Rune Christiansen}

Traducteur : Karin Holter

\section{OpenEdition \\ Journals}

Édition électronique

URL : http://journals.openedition.org/ccs/690

DOI : $10.4000 /$ ccs. 690

ISSN : 2558-782X

Éditeur :

Presses universitaires de Rennes, Association des lecteurs de Claude Simon

\section{Édition imprimée}

Date de publication : 31 décembre 2010

Pagination : 173-174

ISBN : 9782354120771

ISSN : $1774-9425$

\section{Référence électronique}

Rune Christiansen, «La Lumière Complexe », Cahiers Claude Simon [En ligne], 6 | 2010, mis en ligne le

21 septembre 2017, consulté le 15 septembre 2020. URL : http://journals.openedition.org/ccs/690 


\title{
La Lumière Complexe
}

\author{
Par Rune CHRISTIANSEN
}

Une perspective possible serait la suivante : quand on lit Claude Simon, on revient à soi, à sa propre histoire, à ce qui fut... comme si la mémoire était une figure, un stimulant pour toutes nos dispositions, comme si notre faculté de nous souvenir, et ces romans qu'on a lus et qu'on continue de lire, portent en eux l'expression la plus authentique du temps et de l'existence, et à la lumière de cette méta-perspective, on voit que l'œuvre de Claude Simon, ces phrases à mille mots, tous ces commencements et ces fins toujours entamées, jamais accomplies, est un des exemples les plus superbes que la littérature puisse proposer en matière de saisie de la progression de la pensée ou de la mémoire.

Dans l'écriture de Claude Simon, l'histoire est évoquée à travers un dévoilement minutieux des liens saccadés et changeants de la mémoire, et cette mise à nu se fait à l'aide d'un style littéraire exceptionnel : les ramifications méticuleusement tracées des phrases détaillées et interminables qui, à leur tour, créent une perspective unique :

Tout se situe sur le même plan : le dialogue et la sensation, l'action et l'imagination, ce qui est près et ce qui est loin. Et pas dans un ordre chronologique et logique. Simultané et fragmenté. 
Roman après roman, les éléments narratifs et les impulsions associatives forment le tissu d'une conscience particulière, ouverte et mouvante. Les tableaux visuels sont dessinés avec minutie, fourmillant de détails, dans une texture riche. C'est comme si le but de l'écrivain était de saisir et de révéler le fouillis et la plénitude de la mémoire dans tout ce qu'elle a d'inexorable, comme si le moindre détail était entouré d'une infinité de liens :

comme si elles se tenaient toujours là, mystérieuses et geignardes, quelque part dans la vaste maison délabrée, avec ses pièces maintenant à demi vides où flottaient non plus les senteurs des eaux de toilette des vieilles dames en visite mais cette violente odeur de moisi de cave ou plutôt de caveau comme si quelque cadavre de quelque bête morte quelque rat coincé sous une lame de parquet ou derrière une plinthe n'en finissait plus de pourrir exhalant ces âcres relents de plâtre effrité de tristesse et de chair momifiée (Hist. p. 10)

[...] Et même si on refuse de s'adonner au pessimisme, il n'y a aucun doute que l'attente continuelle suscitée par cette œuvre, encore avivée après la publication en 2001 du remarquable Tramway, nous ait tenu en haleine, comme si la possibilité d'un nouveau livre de Claude Simon nous faisait oublier que la littérature est sans chance de réussir, qu'elle est en train de disparaître, une relique déjà... Non, il ne faudrait pas céder à ce découragement impossible à refouler qui nous prend ; mais on a ce sentiment envahissant qu'un des derniers remparts de la littérature vient de tomber... les descriptions élégantes, le temps comme écho, la prose insistante et élégiaque, la lumière complexe qui émane de chaque phrase... 